\title{
Review: statins reduce stroke but not stroke mortality
}

Amarenco P, Labreuche J, Lavallee P, et al. Statins in stroke prevention and carotid atherosclerosis: systematic review and up-to-date meta-analysis. Stroke 2004;35:2902-9.

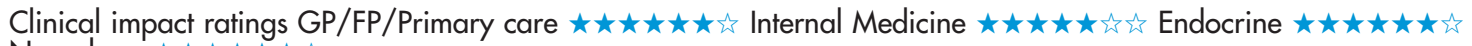

Neurology $\star \star \star \star \star \star \star \star 々$

Do 3-hydroxy-3-methylglutaryl coenzyme A reductase inhibitors (statins) reduce fatal and non-fatal stroke more than placebo or usual care?

\section{METHODS}

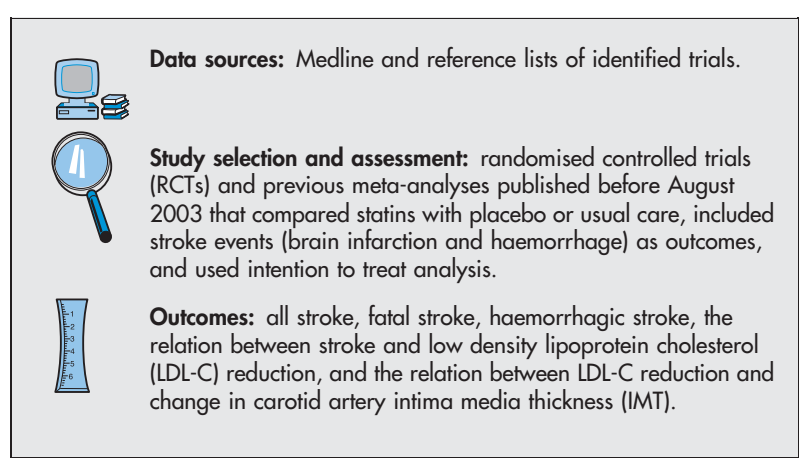

\section{MAIN RESULTS}

26 RCTs $(n=94$ 128) met the selection criteria. Follow up ranged from 0.3 to 6.1 years. Statins reduced all stroke more than placebo or usual care (26 RCTs) (table). Each $10 \%$ reduction in LDL-C corresponded to a risk reduction of all stroke of $16 \%$ (95\% CI 6.7 to 24). The reduction in fatal (15 RCTs) and haemorrhagic (7 RCTs) stroke did not reach statistical significance (table). LDL-C reduction varied from $12-52 \%$, and was correlated with change in carotid IMT. Each $10 \%$ reduction in LDL-C corresponded to a reduction in carotid IMT of $0.73 \%$ per year (CI 0.27 to 1.19 ).

\section{CONCLUSIONS}

Statins reduce stroke but may not reduce fatal stroke. Statins do not increase haemorrhagic stroke. The degree of stroke reduction is correlated with low density lipoprotein cholesterol reduction.

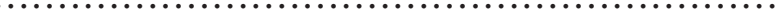
For correspondence: Professor P Amarenco, Bichat University Hospital, Paris, France. amarenco@ccr.jussieu.fr

Sources of funding: PHRC; SOS-ATTAQUE CEREBRALE Association; Formation de Recherche en Neurologie Vasculaire (Association Claude Bernard).

\section{Commentary}

TTertist he trials included in the meta-analysis by Amarenco et al had diverse entry criteria but most required patients to have coronary artery disease or dyslipidaemia. In patients with these conditions, the decision to treat with a statin may be based primarily on concern about subsequent myocardial infarction (MI), which is generally more frequent than stroke. In these patients, the fact that statins also reduce risk of stroke just provides additional motivation for using them.

Patients with previous stroke but no other evidence of vascular disease are more likely to have subsequent stroke than $\mathrm{Ml}$, although rates of both are high. Few of these patients were included in the statin trials completed thus far. However, given that atherosclerosis is a condition common to coronary artery disease and many types of non-haemorrhagic stroke, it is likely that the results of the previous statin trials apply. With a higher underlying rate of stroke in those with previous stroke, the number needed to treat to prevent a stroke is likely to be much smaller. Furthermore, statins have been shown to reduce risk of $\mathrm{Ml}$ in patients with previous stroke in one large scale trial. ${ }^{1}$ Given these benefits, statin use after ischaemic stroke is almost certainly cost effective for most patients.

Although some continued debate exists about whether all patients with previous ischaemic stroke should receive statins and a trial to study this specific question is underway, ${ }^{2}$ most agree that the effect of statins on risk of recurrent stroke and on $\mathrm{Ml}$ is likely to be particularly relevant in this population. In fact, the American Heart Association recently released an advisory stating that the vast majority of patients with previous ischaemic stroke could benefit from statin use.

S Claiborne Johnston, MD, PhD University of California, San Francisco San Francisco, California, USA

$1 \mathrm{MRC} / \mathrm{BHF}$ Heart Protection Study of cholesterol lowering with simvastatin in 20,536 high-risk individuals: a randomised placebo-controlled trial. Lancet 2002;360:7-22.

2 Amarenco P, Bogousslavsky J, Callahan AS, et al. Design and baseline characteristics of the stroke prevention by aggressive reduction in cholesterol levels (SPARCL) study. Cerebrovasc Dis 2003;16:389-95.

3 Statins after ischemic stroke and transient ischemic attack: an advisory statement from the Stroke Council, American Heart Association and American Stroke Association. Stroke 2004;35:1023.

\begin{tabular}{|c|c|c|c|c|c|}
\hline \multirow[b]{2}{*}{ Outcomes at $0.3-6.1$ years } & \multirow[b]{2}{*}{ Number of trials $(\mathrm{n})$} & \multicolumn{2}{|c|}{ Weighted event rates } & \multirow[b]{2}{*}{$\operatorname{RRR}(95 \% \mathrm{Cl})$} & \multirow[b]{2}{*}{ NNT (Cl) } \\
\hline & & Intervention & Control & & \\
\hline $\begin{array}{l}\text { All stroke } \\
\text { Fatal stroke } \\
\text { Haemorrhagic stroke }\end{array}$ & $\begin{array}{l}26(94128) \\
15(71967) \\
7\left(\begin{array}{ll}43 & 758)\end{array}\right)\end{array}$ & $\begin{array}{l}2.9 \% \\
0.68 \% \\
0.29 \%\end{array}$ & $\begin{array}{l}3.4 \% \\
0.69 \% \\
0.34 \%\end{array}$ & $\begin{array}{l}20 \%(14 \text { to } 25) \\
8 \%(-10 \text { to } 23) \\
9 \%(-26 \text { to } 34)\end{array}$ & $\begin{array}{l}222 \text { (163 to } 350 \text { ) } \\
\text { Not significant } \\
\text { Not significant }\end{array}$ \\
\hline
\end{tabular}

*Abbreviations defined in glossary; weighted event rates, RRR, NNT, and Cl calculated from data in article using a fixed effects model. 